\title{
Effectiveness of bite-sized lecture on student learning outcomes
}

Koh, Noi Sian ${ }^{a}$; Gottipati, Swapna ${ }^{b}$ and Shankararaman, Venky ${ }^{b}$

${ }^{\mathrm{a}}$ School of Information Technology, Nanyang Polytechnic, Singapore, ${ }^{\mathrm{b}}$ School of Information Systems, Singapore Management University, Singapore

\begin{abstract}
Bite-Sized teaching approach uses relatively small learning units with shortterm focused activities. The paper presents the effectiveness of Bite-Sized lecture pedagogy on learning outcomes for an analytics course offered by the School of Information Technology at Nanyang Polytechnic. The methodology involves breaking a typical 1 hour lecture into 3 to 4 short lectures followed by related tutorial / practical exercises relevant to each respective short lecture. The results from the exercises shows statistically significant improvements in the assessed learning outcomes for the Bite-Sized lecture over the traditional one hour lecture. $75 \%$ of the surveyed respondents agreed that the speed of course materials presented in the Bite-Sized lecture was just right. Majority of the respondents agreed or strongly agreed that Bite-Sized lecture helped them to learn better. Although this paper is primarily based on education experiences made within an analytics module, the findings presented are applicable to any other computing related courses or even mathematics related courses in general.
\end{abstract}

Keywords: Bite-Sized lecture, mini lecture, short attention span, small learning units 


\section{Introduction}

Research has shown that the digital lifestyles and instant communication technologies have led to a decrease in sustained attention overall. Particularly for those who consume more media, they struggle to focus in environments where prolonged attention is needed. Specifically in the study of content heavy modules with lecture-based delivery still being the dominant form of teaching in many higher education institutions (Bligh, 2000), keeping students engaged through the learning process is an important endeavour. To adapt to changes in the patterns of engagement with learning, this prompted an alternative lecture teaching strategy.

Emerging pedagogies in higher education have applied research findings from areas such as student engagement, information processing, and instructional design to improve teaching practice. For example, by using information about students' attention spans, teachers have included one or two brief rests called focus break in their 50 minute lectures (Stuart \& Rutherford 1978, Johnstone \& Percival 1976). These pedagogical innovations tackle the problems with the way traditional lectures are delivered and have shown that students benefit from changes in teaching practice.

Miller (1956) suggested humans have a limited amount of "working memory" to use when learning. His conception is that the working memory consists of approximately seven chunks. For example, seven random digits are possible to hold in memory relatively easily, but a dozen will be harder without some cognitive tricks. Cognitive Load Theory extends those ideas to suggest that our working memory is subject to certain types of load and that overloading working memory impedes learning. From a cognitive load perspective, BiteSized lectures will help to better manage working memory than the traditional long hours of lectures (Clark et al. 2005).

If the content of the lecture is rich and the pace of presentation is fast, learners may not have enough time to engage in the deeper processes of organizing their thoughts. By the time the learner selects relevant words spoken by the lecturer, then align it with the words and graphics on the presentation slides for one segment of the presentation, the next segment begins, thus cutting short the time needed for deeper processing. This situation leads to cognitive overload in which available cognitive capacity is not sufficient to meet the required processing demands. Sweller (1999) referred to this situation as one in which the presented material has high-intrinsic load; that is, the material is conceptually complex. Although it might not be possible to simplify the presented material, it is possible to allow learners to digest intellectually one chunk of it before moving on to the next.

In prior research, it was found that clinical learners respond best to presentations of topics when they are offered "easily digestible bites" or mini-lessons, presented in tandem with clinical problem-solving (Wyer et al. 2004). Ilse and Shankararaman (2004), presented 
three design models of face-to-face teaching sessions for computing courses extensively using enterprise level systems. They found that mini-lectures followed by laboratory tasks are most successful in scenarios when there is a need to introduce completely new concepts or theories to students. The student is able to acquire new skills and abilities as the linkage of the underlying theories to the practical skill are explained in staggered. This finding highlights the possible effectiveness of better learning experiences by having mini lectures with focused activities related to each mini lecture.

As existing studies on Bite-Sized teaching are qualitative and limited on the quantitative studies, we address the gap in the current literature by assessing the effectiveness of BiteSized lecture approach on the learning outcomes. Thus, we experimented with a course design where the instructor breaks a typical one hour lecture into three to four short lectures. Each short lecture is followed by a related tutorial and practical exercises with reference to various cognitive levels based on the Bloom's taxonomy (Bloom et al. 1956). After each tutorial or practical exercise, the instructor will go through the answers and give immediate feedback and clarifications based on the exercises. This process is iterated over three to four rounds per three hour of face-to-face session. In each session, we assess students based on the learning outcomes related to the topic taught. The findings of the Bite-Sized lecture approach are based on the experiment data which we collected during the teaching sessions.

The rest of the paper is structured as follows: The next section describes the details of course used in our experiment. Subsequently, the dataset collection and the evaluation of the results are discussed, followed by a final section that concludes this work.

\section{Course Design}

The course used in this study was taught to students enrolled in a Specialist Diploma in Business Analytics at the School of Information Technology at Nanyang Polytechnic. The class is taught in the evening and consists of 45 working adults, aged 25 to 65 years old. Majority of the students do not have prior knowledge or background on the subject content. The course content included an introduction to analytics, statistics and predictive modelling. A total of eight weeks of lessons were conducted, with four weeks using the traditional style of teaching (control) (see Figure 1) and four weeks using Bite-Sized teaching (see Figure 2). The classes were held on Wednesday evenings from $6.30 \mathrm{pm}$ to $9.30 \mathrm{pm}$.

In the traditional lecture course design, the session begins with an introduction of the topic, followed by one hour of lecture then one hour of tutorial exercises, one hour of practical / laboratory tasks and finally a wrap up for closure for the three hour lesson. In the Bite- 
Sized lecture course design, the lecture is broken into three to four mini-lectures of 15 to $20 \mathrm{mins}$ each. It is then followed by tutorial exercises and/or practical tasks related to the mini-lecture. Once the student have completed the tutorial exercises / practical tasks, the instructor goes through the answers for the tutorials / practical and then wrap up before proceeding to the next mini-lecture. A common observation during the wrap up for each mini-session is that several students will be asking questions for clarifications related to the lecture, tutorial and/or practical.

The selection on the course design is random for the different topics. As a topic could be taught over a span of few weeks, both course design were used for most of the topics. For example, the topic on inferential statistics is taught using the traditional approach for the first lesson and subsequently for the next lesson, the Bite-Sized lecture approach was used.

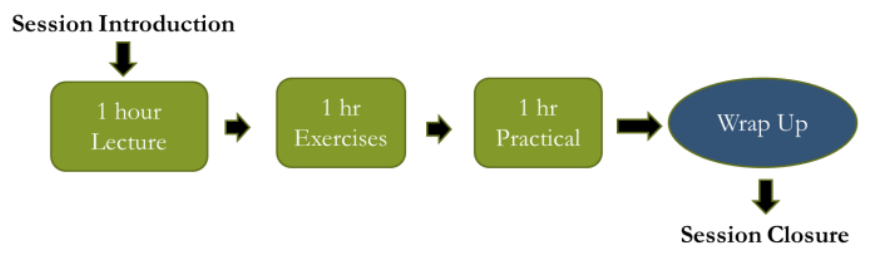

Figure 1. Traditional lecture course design for an analytics course

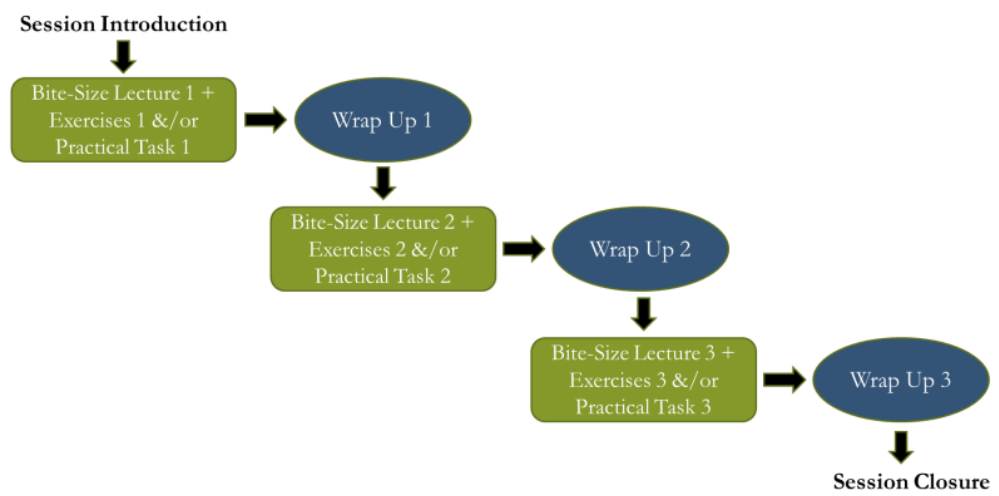

Figure 2. Bite-Sized lecture course design for an analytics course

\section{Results and Discussion}

\subsection{Data}

There are two sets of data collected. One dataset on the scores obtained for each assessed learning outcomes in the topics taught using the two different course designs, the other dataset is a survey conducted at the end of the eight weeks of lessons. We created a survey that primed students to think about the quality of the learning experience using Bite-Sized 
lecture approach. It includes questions on three areas - Competency and Learning Outcomes, Class Delivery, Students' In-Class Behavior. Qualitative feedback was also sought from the participants. There were five absentees when the survey was conducted, hence forty students responded to the survey.

For each lesson, the students were assessed on their learning. The questions tested consist of multiple choice questions and structured questions. All scores allocated for the questions were standardised to a scale of 0 to 10 marks. The questions tested were classified into various cognitive levels (Bloom et al. 1956). Cognitive Level 1 on Remembering, Cognitive Level 2 on Understanding, Cognitive Level 3 on Applying and Cognitive Level 4 on Analysing. (Cognitive Level 5 on Evaluating and Cognitive Level 6 on Creating were out of the scope of the syllabus in this course). Our summative assessments suggest that the Bite-Sized pedagogy produced higher average scores in the course (see Figure 3). Particularly the Bite-Sized teaching approach is better for Cognitive Level 2 on Understanding and Cognitive Level 4 on Analysing. In the Bite-Sized session, it is observed that most of the students were able to answer the questions without referring to the lecture notes whereas in the traditional lecture session, most of the students had to refer to the lecture notes to answer the questions and yet, many were not able to get the correct answer for the questions that requires application and analysis.

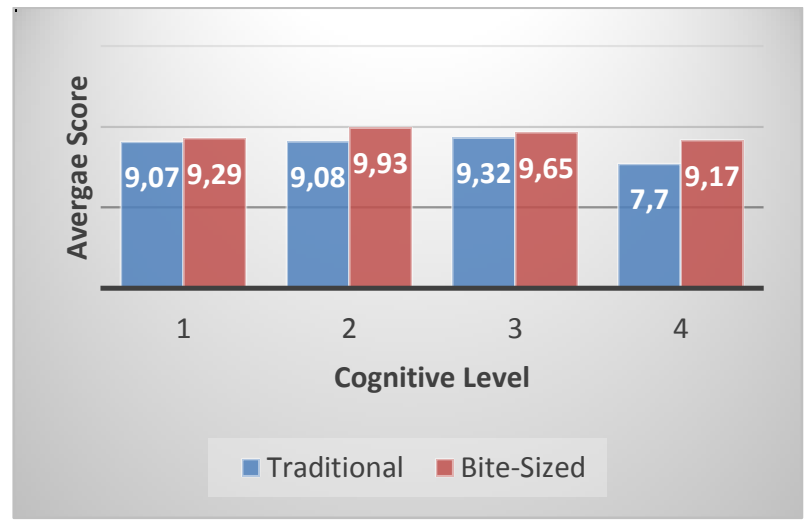

Figure 3. Average score obtained in Traditional course design vs. Bite-Sized course design for the different cognitive levels 


\begin{tabular}{|c|c|c|c|}
\hline \multicolumn{4}{|c|}{$\begin{array}{c}\text { Questionnaire } \\
\text { Number of Students / Survey Respondents: } 40 \\
\end{array}$} \\
\hline \multicolumn{4}{|c|}{\begin{tabular}{|l|l} 
Competency and learning outcomes & \\
\end{tabular}} \\
\hline \multirow{4}{*}{$\begin{array}{l}\text { Rate how useful bite-sized lecture was in helping you to } \\
\text { remember concepts. For example, the question on "Describe } \\
\text { what a model is". }\end{array}$} & Very Useful & $27.5 \%$ & \multirow[b]{2}{*}{$80 \%$} \\
\hline & Somewhat Useful & $52.5 \%$ & \\
\hline & Not very useful & $15 \%$ & \\
\hline & Not useful at all & $5 \%$ & \\
\hline \multirow{4}{*}{$\begin{array}{l}\text { Rate how useful bite-sized lecture was in helping you to } \\
\text { understand concepts. For example, the question on "Explain if } \\
\text { outliers should be removed in the analysis?" }\end{array}$} & Very Useful & $42.5 \%$ & \multirow{4}{*}{$77.5 \%$} \\
\hline & Somewhat Useful & $35 \%$ & \\
\hline & Not very useful & $12.5 \%$ & \\
\hline & Not useful at all & $10 \%$ & \\
\hline \multirow{4}{*}{$\begin{array}{l}\text { Rate how useful bite-sized lecture was in helping you to apply } \\
\text { concepts. For example, the question on "Interpret the } \\
\text { statistical significance of the variables based on the p-value". }\end{array}$} & Very Useful & $42.5 \%$ & \multirow{4}{*}{$87.5 \%$} \\
\hline & Somewhat Useful & $45 \%$ & \\
\hline & Not very useful & $7.5 \%$ & \\
\hline & Not useful at all & $5 \%$ & \\
\hline \multirow{4}{*}{$\begin{array}{l}\text { Rate how useful bite-sized lecture was in helping you to } \\
\text { analyse. For example, the question on "Examine the dataset } \\
\text { and identify the correct statistical test to use". }\end{array}$} & Very Useful & $32.5 \%$ & \multirow{4}{*}{$85 \%$} \\
\hline & Somewhat Useful & $52.5 \%$ & \\
\hline & Not very useful & $12.5 \%$ & \\
\hline & Not useful at all & $2.5 \%$ & \\
\hline
\end{tabular}

Figure 4. Survey on Competency and Learning Outcomes

A T-test was conducted to check the mean difference between the scores obtained in the Traditional course design and the Bite-Sized course design. The T-test results shows that the improvement in test score using Bite-Sized teaching is statistically significant ( $\mathrm{p}$ value $=<0.0001$ ). The survey on competency and learning outcomes (see Figure 4) also indicates that above $75 \%$ of the students find the Bite-Sized lecture helpful for them to remember and understand. Above $85 \%$ of the students find bite-sized lecture helping them to apply concepts and analyze problems. 
Koh, N.S.; Gottipati, S.; Shankararaman, V.

\begin{tabular}{|c|c|c|c|}
\hline \multirow{2}{*}{$\begin{array}{r}\text { Number of Students / Survey Respondents } \\
\text { Questionnaire }\end{array}$} & \multicolumn{3}{|c|}{40} \\
\hline & $\begin{array}{c}\text { (Strongly) } \\
\text { Disagree }\end{array}$ & Neutral & $\begin{array}{c}\text { (Strongly) } \\
\text { Agree }\end{array}$ \\
\hline \multicolumn{4}{|l|}{$\begin{array}{c}\text { Class Delivery } \\
\end{array}$} \\
\hline $\begin{array}{l}\text { Bite-Sized Lecture is preferred over } 1 \text { hour lecture for the teaching of } \\
\text { "Introduction to Statistics". }\end{array}$ & $7.5 \%$ & $32.5 \%$ & $60 \%$ \\
\hline $\begin{array}{l}\text { Bite-Sized Lecture is preferred over } 1 \text { hour lecture for the teaching of } \\
\text { "Descriptive Statistics". }\end{array}$ & $10 \%$ & $27.5 \%$ & $62.5 \%$ \\
\hline $\begin{array}{l}\text { Bite-Sized Lecture is preferred over } 1 \text { hour lecture for the teaching of } \\
\text { "Inferential Statistics". }\end{array}$ & $5 \%$ & $25 \%$ & $67.5 \%$ \\
\hline $\begin{array}{l}\text { Bite-Sized Lecture is preferred over } 1 \text { hour lecture for the teaching of } \\
\text { "Predictive Modelling". }\end{array}$ & $7.5 \%$ & $17.5 \%$ & $75 \%$ \\
\hline $\begin{array}{l}\text { Bite-Sized Lecture is preferred over } 1 \text { hour lecture for the teaching of } \\
\text { "Supervised Learning". }\end{array}$ & $7.5 \%$ & $17.5 \%$ & $75 \%$ \\
\hline $\begin{array}{l}\text { In the Bite-Sized lecture, the speed with which your instructor } \\
\text { presented the course material was just right. }\end{array}$ & $7.5 \%$ & $17.5 \%$ & $75 \%$ \\
\hline $\begin{array}{l}\text { The class exercises are aligned with the content covered during the } \\
\text { Bite-Sized lecture. }\end{array}$ & $12.5 \%$ & $22.5 \%$ & $65 \%$ \\
\hline $\begin{array}{l}\text { The difficulty level of class exercises is manageable in the given } \\
\text { time. }\end{array}$ & $5 \%$ & $20 \%$ & $75 \%$ \\
\hline \multicolumn{4}{|l|}{ Student's In-Class Behaviour } \\
\hline $\begin{array}{l}\text { I am motivated to consume content in short bursts and then } \\
\text { immediately apply the concept to test myself on my skills. }\end{array}$ & $7.5 \%$ & $27.5 \%$ & $65 \%$ \\
\hline $\begin{array}{l}\text { Bite-Sized lectures with exercises enables me to be more focused in } \\
\text { class. }\end{array}$ & $10 \%$ & $30 \%$ & $60 \%$ \\
\hline $\begin{array}{l}\text { Compared to 1-hour lecture, Bite-Sized Lecture encourages me to ask } \\
\text { questions and participate in class discussions. }\end{array}$ & $10 \%$ & $27.5 \%$ & $62.5 \%$ \\
\hline $\begin{array}{l}\text { Compared to 1-hour lecture, in Bite-Sized Lecture, the feedback on } \\
\text { exercises were timely and reinforced my learning. }\end{array}$ & $15 \%$ & $15 \%$ & $70 \%$ \\
\hline $\begin{array}{l}\text { Compared to 1-hour lecture, Bite-Sized Lecture enable me to have } \\
\text { sufficient reflection time. }\end{array}$ & $12.5 \%$ & $22.5 \%$ & $65 \%$ \\
\hline
\end{tabular}

Figure 5. Survey on Class Delivery and Student's In-Class Behavior

Please share your thoughts and suggestions on Bite-Sized lectures 
- Good to recap immediately

- It keeps me focused in class and encourage active learning and application most of the times.

- It was useful in quicker learning process.

- I $\quad$ preferred the bite-sized approach. However, the pace of the lesson could slow down somewhat. Sometimes, before you were able to digest the content thoroughly, you had to move on to the next bit.

- Bite Sized is more effective when the topic involves calculation as we can see how it is applied and how it is interpreted

- cannot concentrate

- $\quad$ Bite Sized lectures are very suitable for the new and tougher topics like predictive modelling

- It breaks the monotony of listening to lecture. It reinforces some of the concepts being taught

- Bit-Sized lecture is effective especially if we are dealing with application type of question, question that need us to digest the concept and understanding and see how the calculation works.

- I find it very useful to help me think, apply and seal in knowledge bit by bit. Many times we assume this $\&$ that, and we think we understand, but this helps me see whether I really understood it or not, what I had just learnt in class or when I am revising at home. So if this is available, it helps in revision at home especially when topics get more difficult, and I need more time to read and ponder before I can fully understand. Way to go.

Figure 6. Qualitative Feedback on Bite-Sized Lectures

In terms of class delivery (see Figure 5), about $60 \%$ of the students surveyed agree or strongly agree that they prefer to be taught using Bite-Sized lecture over the one hour lecture. $75 \%$ agree or strongly agree that the speed in which the instructor presented the materials were just right. Figure 6 presents the qualitative feedback on Bite-Sized lectures. The comments suggested that Bite-Sized lectures helps them in learning new topics and is effective when they are "dealing with application type of question" or when "the topic involves calculation".

\section{Conclusions}

In this paper, we experimented with the Bite-Sized lecture pedagogy to teach an analytics module and assessed its effectiveness in acquiring the learning outcomes. The results show that Bite-Sized lecture offer many advantages over traditional lectures. It can augment student learning by allowing the student to "digest" the content in sections. To the best of our knowledge, this is the first study to evaluate the different types of lecture delivery Traditional vs Bite-Sized, using quantitative assessed learning outcomes. As determined by the questionnaire, the Bite-Sized lecture was more popular than the traditional lecture. We have also provided evidence that the different modes of delivery can affect the different depths of learning as classified by Bloom's taxonomy. Although it seems likely that similar study designs might produce contrasting results depending on the skill and enthusiasm of the teacher, nevertheless the statistical difference in the mean scores in particular areas and survey results suggest effects attributable to the mode of delivery. 
Although this paper is primarily based on education experiences made within an analytics module, the findings presented are equally applicable to any other computing education field or even mathematics related education in general. A number of possibilities exist to extend this study. As the course is taught to adult learners, the results may be due to confounding reasons that may not generalizable for tertiary students. Thus, the same approach can be used and evaluated to see if the results of Bite-Sized lecture still holds for different cohort of students. Future research will be undertaken to investigate this possibility.

\section{References}

Baumgartner, I., \& Shankararaman, V. (2014). Structure of face-to-face teaching sessions for an undergraduate technology-centered computing course: Establishing a set of best practices. In Global Engineering Education Conference (EDUCON), 2014 IEEE (pp. 184-191).

Bligh, D. A. (2000). What's the Use of Lectures? Intellect books.

Bloom, B.S., Engelhart, M.D., Furst, E.J., Hilland, W.H., \& Krathwohl, D.R. (1956). Taxonomy of educational objectives, Handbook I: Cognitive Domain, New York: David McKay, vol. 19, pp. 56.

Clark, R. C., Nguyen, F., \& Sweller, J. (2005). Efficiency in learning: Evidence based guidelines to manage cognitive load. Pfeiffer.

Johnstone, A. H., \& Percival, F. (1976). Attention breaks in lectures. Education in Chemistry, 13(2), 49-50.

Miller, G. A. (1956). The magical number seven, plus or minus two: some limits on our capacity for processing information. Psychological Review, 63(2), 81-97.

Stuart, J., \& Rutherford, R. J. D. (1978). Medical student concentration during lectures. The Lancet, 312(8088), 514-516.

Sweller, J. (1999). Instructional Design in Technical Areas. Camberwell, Australia: ACER Press.

Wyer, P. C., Keitz, S., Hatala, R., Hayward, R., Barratt, A., Montori, V. Montori \& Guyatt, G. (2004). Tips for learning and teaching evidence-based medicine: introduction to the series. Canadian Medical Association Journal, 171(4), 347-348. 